\title{
Developing an Interoperability Framework for Building Information Models and Facilities Management Systems
}

\author{
Sandra T. Matarneh ${ }^{\mathrm{a}}$, Mark Danso-Amoako ${ }^{\mathrm{b}}$, Salam Al-Bizri ${ }^{\mathrm{a}, \mathrm{b}, *}$, Mark Gaterell, Rana Matarneh \\ ${ }^{a}$ University of Portsmouth, School of Civil Engineering and Surveying, Portsmouth PO1 2UP, UK \\ ${ }^{b}$ University of Portsmouth, School of Civil Engineering and Surveying, Portsmouth PO1 2UP, UK
}

\begin{abstract}
Despite the fact that the value of extending Building Information Modeling (BIM) implementation through the operations and maintenance phase is simply to reduce the operations and maintenance costs associated with inadequate interoperability, facilities management information flow is neither automated nor seamless. Facility managers do not normally use BIM models data, since they claim that BIM models either do not include their information requirements, or contain a huge amount of superfluous data which makes the data exchange process tedious and overwhelming. Construction Operations Building information exchange (COBie) is developed to improve the facility data handover and to support facilities management systems. However, COBie add-in existing applications have their inherent limitation to generate all facilities management required data, particularly spare, resource and job data sheets, in which a manual data entry is still required. Through a series of interviews with industry practitioners, this paper analyses current data exchange practices as well as proposed a conceptual interoperability framework for seamless data exchange between BIM models and facilities management systems. A proposed database information system that automatically generates a rich COBie spreadsheet by linking BIM data models via the Industry Foundation Classes (IFC) model to facilities management information provided by various sources. The proposed framework supplements the existing body of knowledge in facilities management domain by providing a system that facilitates seamless data transfer between BIM and facilities management systems. Facilities management organisations and owners can use this approach to decrease the redundant activity of manual data entry and focus their efforts on productive maintenance activities.
\end{abstract}

(C) 2018 The Authors. Published by Diamond Congress Ltd., Budapest University of Technology and Economics Peer-review under responsibility of the scientific committee of the Creative Construction Conference 2018.

Keywords: BIM, COBie, data exchange, facilities management, interoperability.

\section{Introduction}

For a Facilities management (FM) team with multiple projects to manage, effective management of facility assets is a necessity for sustaining the maintainability, safety and reliability of a facility assets, which in turn supports organizations to achieve sustained level of operational productivity and safe working environment $[1,2]$. Knowing that the Operation and Maintenance (O\&M) is the longest and most expensive phase during the facility's lifecycle; which constitutes about three times the construction cost [3], accounts for $(75-85 \%)$ of the total costs spent over the building lifecycle $[4,5]$, and holds the responsibility for major organization assets that often forms (35-50\%) of its balance sheet [6]. Thus, controlling O\&M costs can have a considerable impact on the industry in terms of trillions of dollars of cost savings [7]. The key challenge for FM team, is to have an accurate and comprehensive information system that enables capturing and retrieving building components and systems data $[8,9]$.

Corresponding author: Author email: Sandra.matarneh@port.ac.uk 
In most current practices, FM data is collected from paper handover documents and is re-entered manually in one of the computerized information systems such as "Computer-Aided Facility Management (CAFM)" and "Computerized Maintenance Management Systems (CMMS)" [10]. Most of the existing information systems that support FM operations often develop gradually during the O\&M phase, and reside underutilized in disparate databases that often lack interoperability capability $[10,11]$. Moreover, the manual entry of FM data into different individual systems is costly and time consuming process which can be extended up to six months to finalize this task [12, 13].

According to the National Institute of Standards and Technology (NIST), two-thirds of the estimated \$15.8 billion lost in the U.S capital facilities industry are associated with inadequate interoperability during the O\&M phase, to cover for expenses related to manual data re-entry, data verification, redundancy and idle labor time finding relevant data that is often unavailable $[6,12,14]$.

Building Information Modeling (BIM) can offer an information conduit and repository to support FM activities [15]. BIM proved its success in design and construction phases, but also proved its invaluable potential to support FM team during the O\&M phase [13, 16-18]. Governments such as those in the UK are driving to promote a potential improvement for data handover process in the form of COBie to support its BIM Level-2 mandate [19-21]. BIM can potentially enable data sharing and exchange between different stakeholders during the facility's lifecycle [22]. Yet in the most current practice, over (70\%) of completed construction projects fail to deliver BIM models and corresponding COBie spreadsheet at the project's handover stage for the owner and FM team use [23].

Studies of current FM practice show that most of BIM models data is often created and accumulated throughout the design and construction phases of the facility and does not necessarily take full consideration of FM requirements to support its operations [24]. Moreover, there are commercially available technologies focus on transferring data between BIM models and FM systems, but the process of pushing BIM models outputs to FM systems inputs is not a straightforward process or cost effective. There is a need for best practices for data transfer strategies to be developed and documented. Therefore, in this research, we propose a conceptual interoperability framework for data exchange by linking BIM models outputs along with various stakeholders' outputs to FM systems inputs. In our approach, the system is developed through an intelligent external database that enables various data sources to be added and retrieved. The proposed approach processes FM data provided by different stakeholders along with specific outputs extracted from BIM models to automatically generate a rich COBie data spreadsheet that includes most of the required outputs to support FM systems.

\subsection{Facilities management information}

Today's facilities are ever more sophisticated and the need for available and reliable information for O\&M activities is vital [6]. Most of this needed information are often created and accumulated throughout the design and construction phases and is often handed over to the owner/ FM team when the construction is completed in the form of paper and/or electronic copies. This late delivery of unstructured data, causes a serious challenge for owners/FM team to check and verify whether the delivered information includes FM requirements in order to perform their activities efficiently [10, 13]. It is acknowledged that BIM improves information management during the O\&M phase $[10,8]$. The more accurate and real-time information is available for facility managers, the greater the opportunity for the enhancement of processes throughout the O\&M phase. One of the key success factors for BIM implementation in FM, is to identify the required data for FM team day-to-day activities [26, 27].

Accordingly, the industry started to acknowledge the importance of having a standardization for data format and specification and issued standards that support data management such as PAS 1192:1,-5 to improve semantic data interoperability. For example, COBie standards were developed to improve the facility handover process by providing a non-geometric structured data available for the FM team use [28 - 30]. However, according to Love, et al. [31], COBie and the FM Handover MVD "provide a structure for the information the owner needs, but they do not support the owner with what to populate them with in order to receive value later in the lifecycle". Thus, identifying the required BIM data outputs for FM systems inputs is critical [32]. Several studies tried to tackle this topic and highlighted the necessity of identifying the required FM data. Becerik-Gerber et al. [11] listed the application areas of BIM in FM and clarified how each application requires a specific data requirements. Sattenini et al. [33] attempted in their research to identify the required FM information to be considered in BIM models using a case study approach of a university building. Mayo and Issa [34] investigated the required non-geometric building information to support FM operations through a Delphi panel of FM experts. While Cavka et al. [35] conducted a study using a university building to identify the required data for maintenance, systems monitoring and assets management activities. Finally, a study conducted by Dias \& Ergan [36] identified the required data for HVAC systems maintenance. Most of the researchers mentioned 
that data requirements vary according to the building use and owner requirements. However, having a standardized approach to identify data requirements for FM team use remains challenging.

\subsection{Data exchange and interoperability}

Theoretically, BIM works as a collaborative platform that facilitates an automatic seamless data flow between different stakeholders throughout a facility's lifecycle [37], and eventually, provides FM team with an accurate and reliable information database [38]. However, in actual practice, data flow is neither automated nor seamless and FM team still key relevant data into their computerized FM systems manually [38, 39]. Although standard data formats are capable of exchanging data between different platforms, particularly the Industry Foundation Classes (IFC) and COBie schemas, the data exchange process between BIM data models and FM systems is not a straightforward process. For instance, the integration between BIM and CAFM has been heavily criticized for limited data interoperability, particularly the ability of transferring proper FM semantic data [40]. Recent research acknowledge that, although BIM enables data flows easily among facility's lifecycle using an interoperable data formats - yet data exchange between BIM and FM systems and interoperability, remain problematic [24, 11, 40-45].

Recently, several research conducted to tackle the issue of data exchange and interoperability focused on one or two of the following topics: (1) the value of using BIM to enhance the handover process [46, 47, 31], the need to identify FM information [11,34], (2) the use of open data standards such as COBie and IFC to transfer data between BIM and FM [46, 48 - 52], (3) the efficiency of using different technologies such as barcode and augmented reality along with BIM to improve FM operations [53-58]. The existing literature indicates that seamless facility data exchange cannot be optimized by straightforward adoption of BIM as a database tool; and it further shows that project stakeholders should also consider a new BIM-enabled processes that enable capturing facility data and then exchange it using open data formats, that allow the potential interoperability with different FM systems. Moreover, the existing literature indicates that interoperability remains a significant and persistent challenge for using BIM to support FM operations. Thus, more research is needed to further substantiate the potential of seamless data exchange between BIM and FM systems.

\section{Research method}

The overarching aim of this research is to develop the conceptual framework for seamless data transfer between BIM and FM systems. The development of this framework necessitates a general understanding of the current status of data exchange methods and requirements. Accordingly, we used semi-structured interviews method to collate more views from the industry practitioners on the current data exchange method and requirements. A total of 16 BIM experts participated in the research interviews from different organizations as shown in Table (1). Results of the interviews helped in outlining the general approach for the proposed interoperability framework as discussed in section (4) and presented in section (5).

\section{Research results}

Interviews transcripts were analyzed using a thematic analysis approach. The interviews covered two themes: (1) data handover process deliverables; (2) data exchange methods and requirements. Interviewees were selected from different industry stakeholders to collate different perspectives as presented in Table (1). Interviewees representing FM organizations formed (37.5\%), followed by interviewees representing both contracting and BIM consultancy organizations (25\%) each, and interviewees representing architect/engineering organizations $(12.5 \%)$.

Table 1. Interviewees' demographic distribution

\begin{tabular}{lll}
\hline Interviewees' organization type & No. & Percentage (\%) \\
\hline Facility Management & 6 & 37.5 \\
Contracting & 4 & 25.0 \\
Architect / Engineering & 2 & 12.5 \\
BIM consultant & 4 & 25.0 \\
\hline
\end{tabular}




\subsection{Data handover deliverables}

Interviewees were asked about projects' data handover required deliverables using BIM, and most of the interviewees chose at least three deliverables out of five provided. All interviewees (100\%) mentioned that the electronic copy of scanned construction documents (EC) and BIM as-built models (BIMS) were required for handover. While (56\%) of the interviewees stated that paper copy of construction documents (PC) was required as well, and (50\%) of the interviewees added COBie as another deliverable as shown in Fig.1. Only (6\%) of the interviewees added IFC file as a handover deliverable.

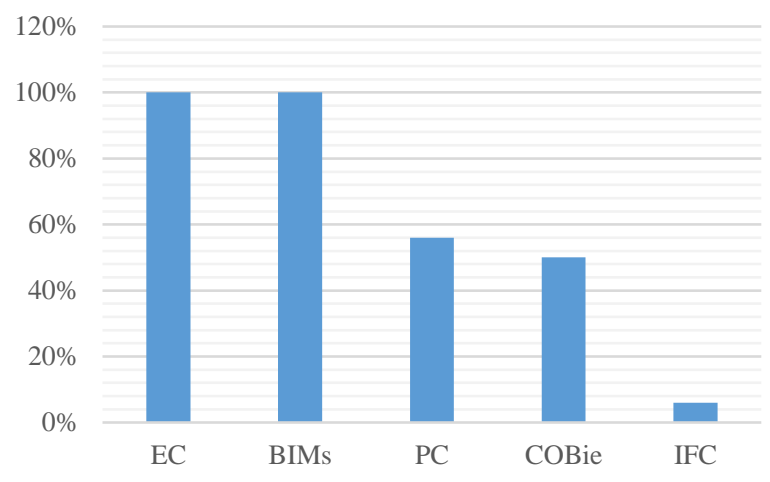

Fig. 1. Handover deliverables

Interviewees were asked about how they hand over data related to periodic preventive maintenance, spare parts and operating environment issues. All interviewees agreed that this type of data is normally delivered within the O\&M manuals as a scanned electronic copy (.pdf).

\subsection{Data exchange methods and requirements}

Interviewees were asked about data exchange methods which were used in their projects to transfer data between BIM and FM systems. The majority of the interviewees (56\%) stated that data was transferred manually although BIM as-built models were delivered to the owner. While (19\%) of the interviewees stated that they used either a middleware software such as Ecodomus or COBie spreadsheet as presented in Fig.2. While (6\%) of the interviewees presented as "other" clarified that they used other methods such as BIM 360 environment to share data with FM team.

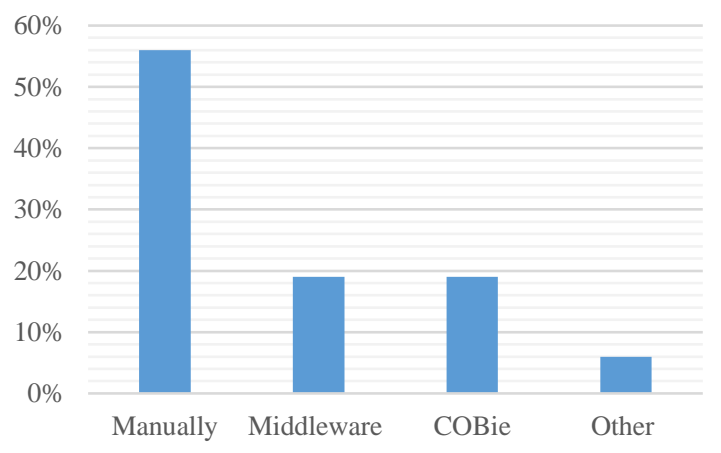

Fig. 2. Data exchange method between BIM and FM

Interviewees were asked about their opinion of the most efficient method to transfer data seamlessly between BIM and FM systems. Most of the interviewees as presented in Fig.3. (63\%) selected COBie. While (19\%) of the interviewees indicated that IFC is more efficient for data exchange process and (13\%) stated that FM systems vendors 
should start thinking about direct integration between FM systems software and BIM models. Only (6\%) of the interviewees found that a middleware software can be the best method.

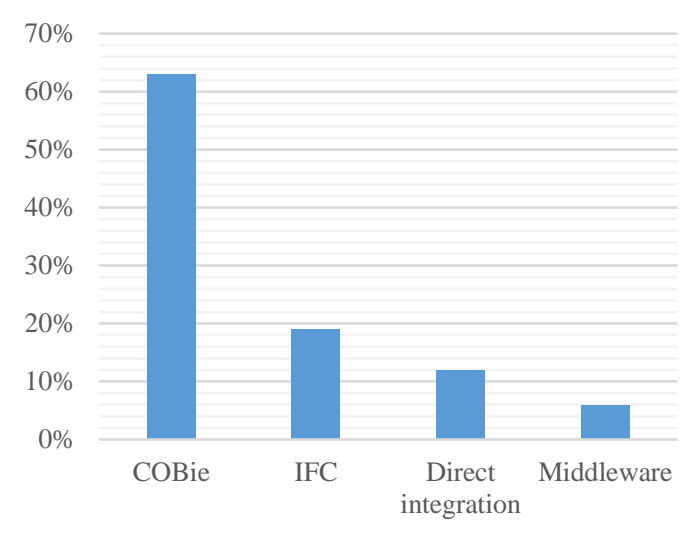

Fig. 3. The most efficient data exchange method between BIM and FM

Finally, the interviewees were asked if COBie spreadsheet includes all required FM information. All interviewees agreed that COBie add-in existing applications do not generate all the required FM information. Furthermore, the interviewees were asked to give examples of the required information which are not included in COBie spreadsheet, these examples are: periodic preventive maintenance schedules, spare parts, legislative compliance requirements, consumables and safety issues. The interviewees were asked then to list the required BIM outputs for their FM systems inputs and they listed different types of data as presented in Table (2).

Table 2. Interviewees' feedback on the required BIM outputs of FM system inputs

\begin{tabular}{ll}
\hline Items & Required information \\
\hline Maintenance management & $\begin{array}{l}\text { Maintenance schedules (preventive and reactive), Legislative } \\
\text { compliance requirements }\end{array}$ \\
Asset management & $\begin{array}{l}\text { Asset register, Asset ID, Description, Location, Type, Subtype, Bar } \\
\text { code, Classification, Rotating item, Serial \#, Warranty information, }\end{array}$ \\
& Tag \#, Specifications, Spare parts list, \\
Planning and scheduling & $\begin{array}{l}\text { PM activities, Durations, Frequencies, Resources (tools, labor and } \\
\text { material) }\end{array}$ \\
Supply chain management & $\begin{array}{l}\text { Vendor information, Manufacturer information, Installation date, } \\
\text { Replacement cost, Expected useful life, Purchase order \# , } \\
\text { Consumables }\end{array}$ \\
& Codes and requirements
\end{tabular}

\section{Discussion}

The interviews results shaped the general understanding of the current status of using BIM to support FM operations. Interestingly, interviews results show that for some projects where BIM is used to support FM operations, manual data entry was used to enter FM data into FM systems software. Interviewees clarified that COBie and BIM as-built models were stated clearly in the Employer Information Requirements (EIR), but FM team opted to enter data manually into their FM systems as they could not manage to deal with COBie spreadsheet. On the other hand, interviewees who used COBie as a database for their FM systems asserted that COBie spreadsheet did not include all FM required data such as the preventive maintenance data in which they had to enter this data manually into their FM systems. Therefore, having a seamless data exchange process between BIM and FM systems will save a considerable amount of time and effort. 


\section{Conceptual framework}

Analysis of the data confirms the importance placed by industry professional on potential seamless data transfer between BIM and FM systems, and how specific asset information requirements are needed to reduce the redundant effort of generating BIM outputs that don't match the FM systems inputs. Fig.4. shows a proposed seamless data transfer process using specific asset information requirements to be considered in BIM models and then export these required outputs to external intelligent database using IFC schema. Other data related to preventive maintenance and spare parts will be added to and retrieved from the same database using various sources such as the industry standards (SFG20 .xml) and spare parts spreadsheet .xlsx. A rich COBie spreadsheet will be generated using COBie-lizer module to include FM data requirements.

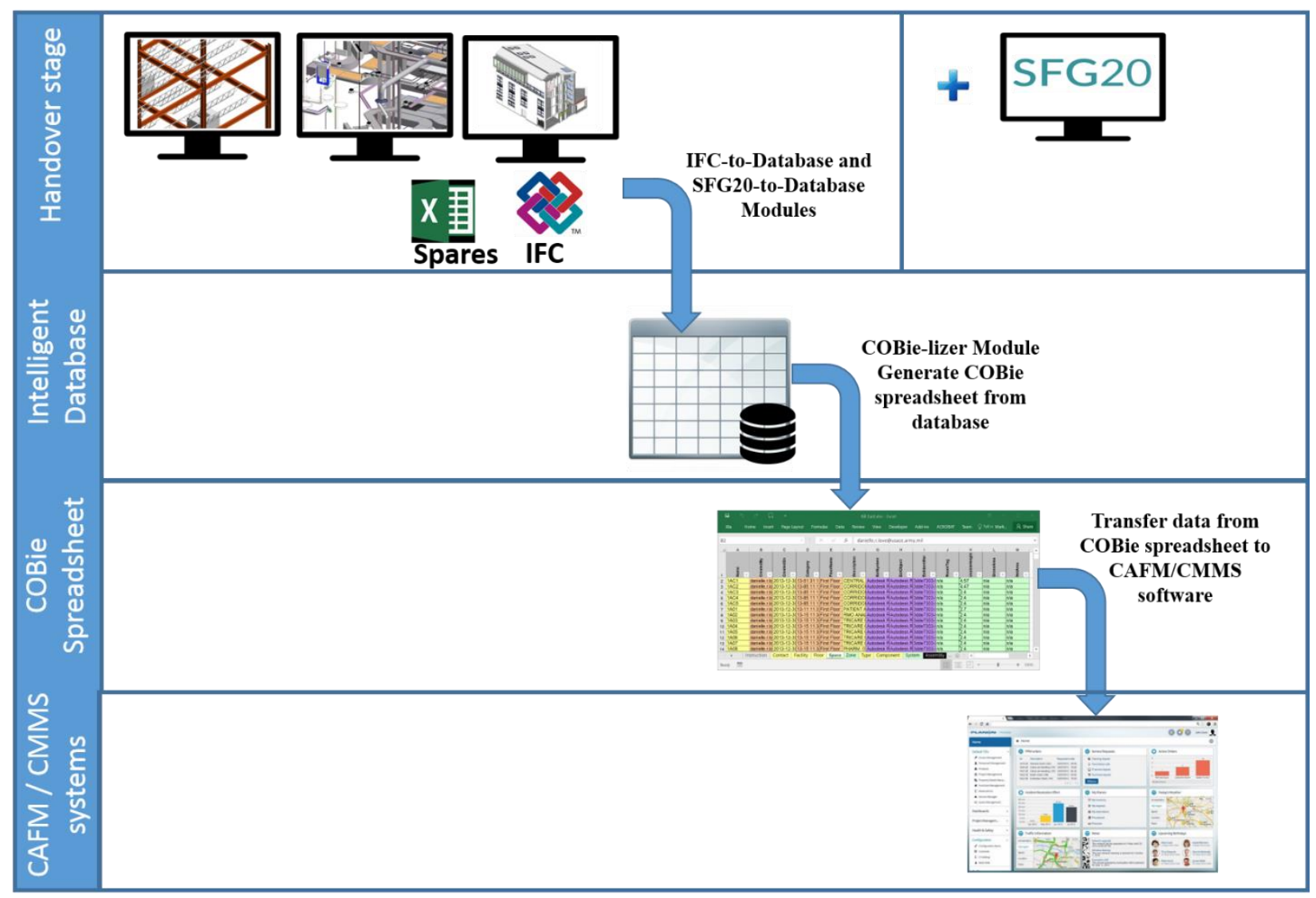

Fig. 4. The conceptual framework for seamless data exchange between BIM data models and FM systems

The proposed framework consists of the stages and inter-stage processes detailed below:

- Stage I: At this stage in the project's life cycle, facility data has been captured at different phases by various stakeholders, and stored in the form of a BIM model. These BIM as-built models include a huge amount of both geometric and non-geometric data about the facility. This data can be obtained from the model in the form of IFC (design deliverable view) as shown in Fig.5. which the majority of BIM-enabled authoring tools are capable of producing. The first component of the proposed framework is to process the IFC file into entities ready for storage in a relational database. 


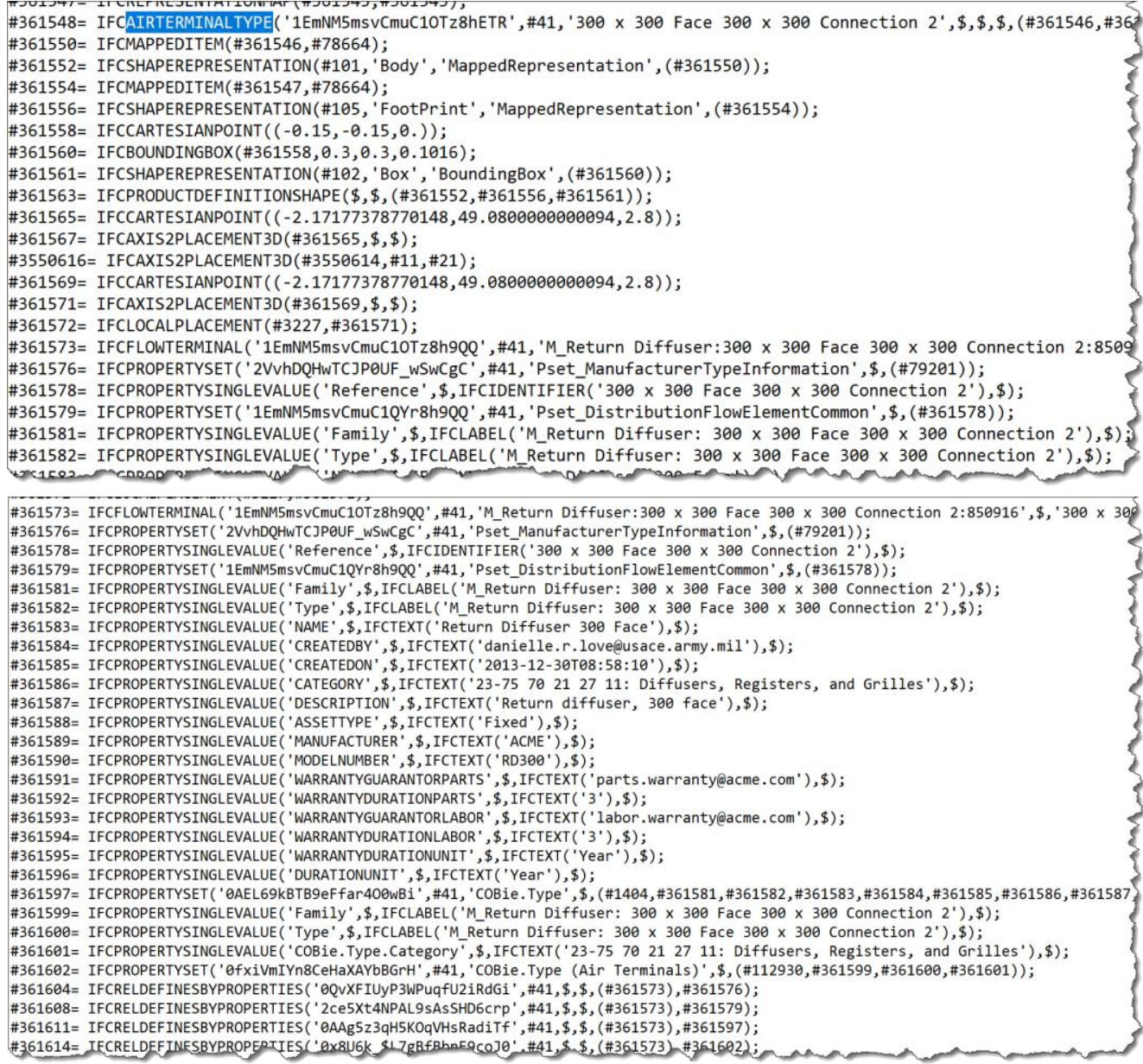

Fig. 5: IFC2×3 COBie 2.4 Design Deliverable View

- Stage II: Unfortunately as discussed previously, some of the required vital data relating to maintenance is not included in the BIM as-built model IFC files. The required data can be collated from various sources such as SFG20 (the de-facto maintenance standard) which includes preventive maintenance schedules (actions, durations, frequencies and resources) and related legislative compliance requirements as shown in Fig.6. Spare parts log is another data source usually prepared by the general contractor during the construction phase for handover in the form of a spreadsheet. This spreadsheet now resides outside the 3D BIM model and hence not included in the IFC file during export. All data collected at this stage is inputted to the external database for further data manipulation. 


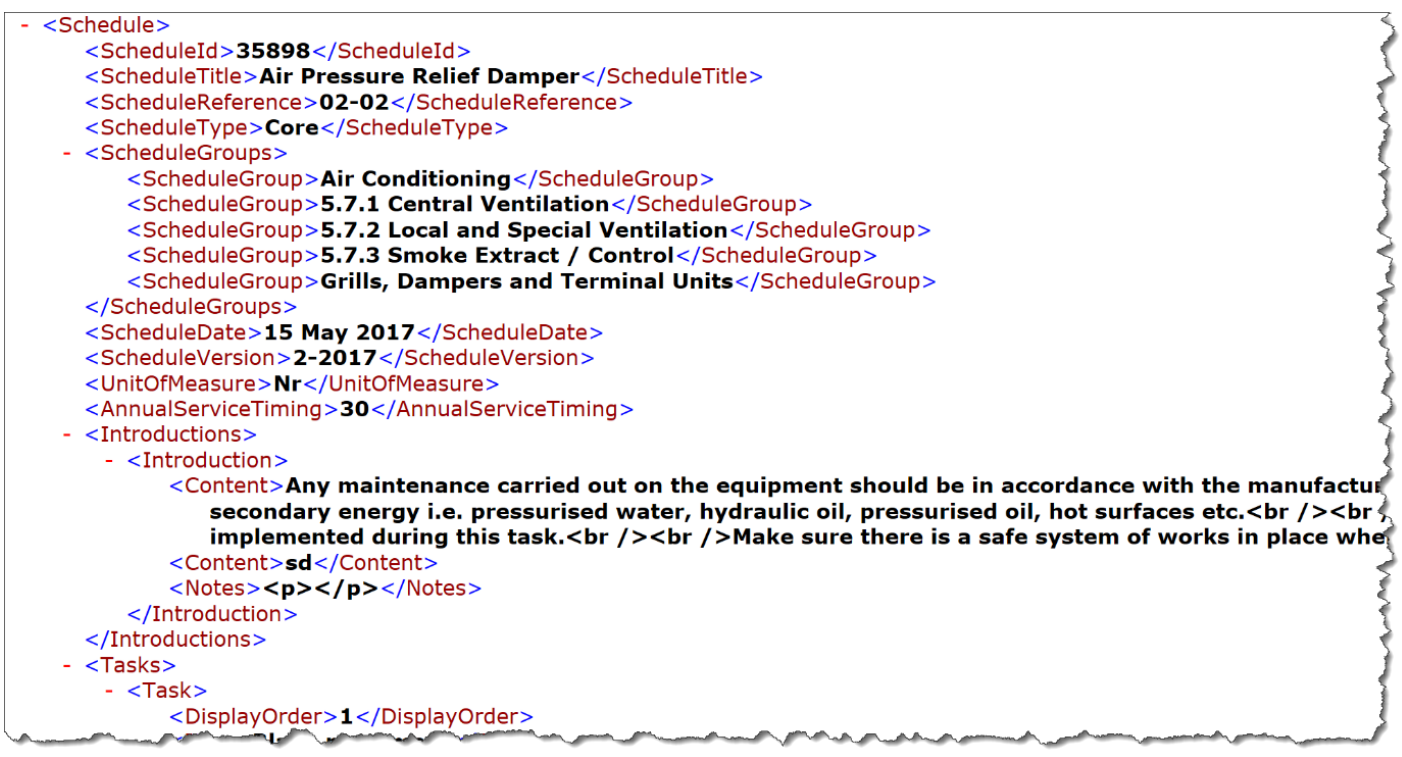

Fig. 6. Exporting SFG20XML

- Stage III: At this stage, the external database would have been fully populated with data from the IFC files, SFG20 data schema and any auxiliary spreadsheets such as the spare parts logs. This rich data is then processed through the proposed COBie-lizer module which takes in these inputs and automatically generates a fully compliant COBie spreadsheet. This COBie-lizer module will be developed based on relationship-mapping between the external database and COBie sheet schema.

- Stage IV: At this stage, there are full sets of COBie spreadsheet data developed from stage III. With COBie being an internationally accepted standard for managing asset information including space and equipment, direct data transfer between COBie spreadsheet and CMMS/CAFM software can be done seamlessly.

\section{Conclusions and recommendations}

Through the development of the proposed conceptual framework, we have come to understand the importance of interoperability between BIM models and FM systems and advocate the focus on the development of seamless data transfer process within the research community. A key question in this area is, "to what level can data be transferred and managed seamlessly between BIM models and FM systems?" Asset Information Requirements (AIR) which have mainly focused on room numbers, floor areas, space use and asset register, can host more relevant building maintenance data such as preventive maintenance outputs. Moreover, the participants' feedback assert the general understanding that data exchange between BIM models and FM systems is not a straightforward process. Managing a huge amount of data collected from various stakeholders using COBie data structure is helpful - yet the existing COBie add-ins applications do not allow for automatic generation of all required FM data. Accordingly, we developed a conceptual framework that allows for the required data to be collected and retrieved at different levels and then transferred seamlessly to the FM systems using an open standard format. The proposed conceptual framework will be implemented by developing a module "COBie-lizer" to generate a rich COBie spreadsheet and then tested in future research. Findings in this domain could be of great interest to owners and facility managers who currently struggle with their current information management systems.

\section{Acknowledgements}

The authors would like to acknowledge the help and support of industry practitioners who participated in the research interviews and questionnaire survey. The proposed conceptual framework could not be done without the valuable information they provided. 


\section{References}

[1] B. Atkin, A. Brooks, Total Facilities Management. s.1.:Wiley-Blackwell, 2009.

[2] P.S. Barrett, Facilities Management Towards Best Practice, Blackwell Science, London, 1995.

[3] S. Fuller, Life-Cycle Cost Analysis (LCAA), 2010. (Retrieved May 4, 2017, from http://www.wbdg.org/resources/life-cycle-cost-analysis-lcca).

[4] J. Richard, A. Kirkham, Boussabaine Halim, Awwad H. Belal, Probability distributions of facilities management costs for whole life cycle costing in acute care NHS hospital buildings, Construction Management and Economics 20 (2002) 251-261.

[5] J. Marchese, C. Rudderow, The Power of 3D: Using BIM for Facility Management, 2013. (Retrieved from

http://www.areadevelopment.com/Asset Management/Q2-2013/buildinginformation-modeling-facilitymanagement-0272892.shtml).

[6] D. A. Jordani, BIM and FM: the portal to lifecycle facility management, Journal of Building Information 6 (2010) 13-16.

[7] Y. Arayici, T. Onyenobi, C. Egbu, Building Information Modelling (BIM) for Facilities Management (FM): The Mediacity Case Study Approach. International Journal of 3-D Information Modeling, 1(2012), 55-73.

[8] I. Motawa, A. Almarshad, A knowledge-based BIM system for building maintenance. Journal of Automation in Construction, 29 (2013), 173182.

[9] K. Kensek, BIM Guidelines Inform Facilities Management Databases: A Case Study over Time. Buildings, 5 (2015), pp. $899-916$.

[10] P. Teicholz, BIM for facility managers. John Wiley \& Sons, New Jersey, U.S, 2013.

[11] B. Becerik-Gerber, F., Jazizadeh, N. Li, G. Calis, Application areas and data requirements for BIM-enabled facilities management. Journal of construction engineering and management, 138(2012), pp. 431-442.

[12] M. P. Gallaher, A.C. O’Connor, J.L. Dettbarn, L.T. Gilday, Cost Analysis of Inadequate Interoperability in the U.S. Capital Facilities Industry, National Institute of Standards and Technology, 2004. (Retrieved January 18, 2017, from http://fire.nist.gov/bfrlpubs/build04/art022.html).

[13] J. Patacas, N. Dawood, V. Vukovic, M. Kassem, BIM for facilities management: evaluating BIM standards in asset register creation and service life. Journal of Information Technology in Construction (ITcon), Volume 20 (2015), 313-331.

[14] R. Rundell, How can BIM benefit facilities management, 2006. (Retrieved January 13, 2017, from http://www.cadalyst.com/cad/buildingdesign/1-2-3-revit-bim-and-fm-3432).

[15] L. Sabol, Challenges in cost estimating with building information modeling, IFMA World Workplace, 2008. (Retrieved January 2017, from: http://www.dcstrategies.net/files/2_sabol_cost_estimating.pdf).

[16] M. Kassem, K. Graham, G. Kelly, M. Serginson, S. Lockley, BIM in facilities management applications: a case study of a large university complex, Built Environment Project and Asset Management - Emerald, 5(2015), 261-277.

[17] R. Volk, J. Stengel, F. Schultmann, Building information modelling (BIM) for existing buildings: literature review and future needs. Automation in Construction, 38 (2014), 109-127.

[18] A. Motamedi, A. Hammad, Y. Asen, Knowledge-assisted BIM-based visual analytics for failure root cause detection in facilities management. Automation in Construction, (2014) 73-83

[19] E. W. East, N. Nisbet, T. Liebich, Facility Management Handover Model View. Journal of Computing in Civil Engineering, 27(2013) 61-67.

[20] M. Kassem, N. Iqbal, N. Dawood, A practice oriented BIM framework and workflows. International Workshop on Computing in Civil Engineering, (2013) 524-532.

[21] BIMTaskGroup. Bilduing information modelling task group, 2013, (Retrieved from http://www.bimtaskgroup.org/).

[22] Y. Jung, M. Joo, "Building information modeling (BIM) framework for practical implementation", Automation in Construction, Vol. 20 No. 2, (2011) 126-133.

[23] R. Eadie, M. Browne, H. Odeyinka, C. McKeown, S. McNiff, BIM implementation throughout the UK construction project lifecycle: An analysis. Automation in Construction, 36 (2013) 145-151.

[24] Azhar, S. (2011). Building Information Modeling (BIM): Trends, Benefits, Risks, and Challenges for the AEC Industry. ASCE Journal of Leadership and Management in Engineering, 11(3), 241-252.

[25] Eric M. Wetzel, Walid Y. Thabet, A case study towards transferring relevant safety information for facilities maintenance using BIM. Journal of Information Technology in Construction (ITcon), Vol. 23(2018) 53-74.

[26] R Liu, R.R. Issa, Survey: common knowledge in BIM for facility maintenance, Journal of Perform.Constr. Facili. Vol. 30 (2016) 04015033.

[27] P. Parsanezhad, V. Tarandi, Is the age of facility managers' paper boxes over?, Proceedings of the CIB World Building Congress, Technical University of Denmark, Copenhagen, 21-23 May 2014.

[28] C. Eastman, P. Teicholz, R. Sacks, K. Liston, BIM Handbook: A Guide to Building Information Modeling for Owners, Managers, Designers, Engineers and Contractors. New York: John Wiley and Sons, 2011.

[29] A. Bosch, L. Volker, A. Koutamanis, BIM in the operations stage: Bottlenecks and implications for owners. Built Environ. Proj. Asset Manag, 5(2015) 331-343.

[30] W. Thabet, J. Lucas, S. Johnston, A Case Study for Improving BIM-FM Handover for a Large Educational Institution. San Juan, Puerto Rico, Construction Research Congress 2016.

[31] P. E. Love, J., Matthews, I., Simpson, A., Hill , O.A., Olatunji, A benefits realization management building information modeling framework for asset owners. Autom. in Constr., Volume 37 (2014), pp. 1-10. , http://dx.doi.org/10.1016/j.autcon.2013.09.007.

[32] A. Sattenini, S. Azhar, J. Thuston, Preparing a building information model for facility maintenance and management. Seoul, South Korea, 28th International Symposium on Automation and Robotics in Construction, (2011) 144-149.

[33] G. K. Mayo, R. R. A. Issa, Nongeometric Building Information Needs Assessment for Facilities Management. Journal of Management in Engineering, 32(2016).

[34] H. B. Cavka, S. Staub-French, R. Pottinger, Evaluating the Alignment of Organizational and Project Contexts for BIM Adoption: A Case Study of a Large Owner Organization. Buildings, Volume 5, (2015) 1265-1300.

[35] P. Dias, S. Ergan, The Need for Representing Facility Information with Customized LOD for Specific FM Tasks. San Juan, Puerto Rico, Construction Research Congress, CRC 2016. American Society of Civil Engineers (ASCE), (2016) 2563-2572. 
[36] R. Liu, R. R. Issa, Automatically Updating Maintenance Information from a BIM Database. ASCE TCCIT International Conference on Computing in Civil Engineering, 2012.

[37] J. Lee, M. Lee, S. Lee, S. Oh, B. Kim, S. Nam, J. Jang, Development of computerized facility maintenance management system based on reliability centered maintenance and automated data gathering, Int. J. Control Autom. SERSC 6 (2013) 1-12.

[38] W. East, W. Brodt, BIM for construction handover. Journal of Building Information Modeling, (2007) 28-35.

[39] W. E. East, B. William, BIM for Construction Handover, Journal of Building Information Modeling, (2007) 28-35.

[40] BIFM, 2013. Bishop's Stortford, Hertfordshire, UK.: British Institute of Facilities Management.

[41] G. Kelly, M. Serginson, S. Lockley, BIM for facility management: a review and a case study investigating the value and challenges. London, UK, the 13th International Conference on Construction Applications of Virtual Reality 2013.

[42] P.E. Love, J. Matthews, I. Simpson, A. Hill, O.A. Olatunji, A benefits realization management building information modeling framework for asset owners, Autom. Constr. 37 (2014) 1-10.

[43] Y. Ham, M. Golparvar-Fard, Mapping actual thermal properties to building elements in gbXML-based BIM for reliable building energy. Automation in Construction, Volume 49, (2015) 214-224.

[44] E. Wetzel, W. Thabet, The use of a BIM-based framework to support safe facility management processes. Automation in Construction, Issue 60, (2015) 12-24.

[45] K. Ibrahim, F. Abanda, C Vidalakis, G Woods, BIM for FM: Input versus Output data. Brisbane, Australia, 33rd CIB W78 Conference 2016.

[46] A. K Nicał, W. Wodyńskib, Enhancing Facility Management through BIM 6D. Procedia Engineering, Volume 164, (2016) $299-306$.

[47] W. Wu, R. R. A., Issa, BIM-Enabled Building Commissioning and Handover. Clearwater Beach, Florida, United States, International Conference on Computing in Civil Engineering, 2012.

[48] S. P. Jawadekar, A Case Study of the Use of BIM and Construction Operations Building Information Exchange (COBie) for Facility Management. Texas: Texas A\&M University, 2012.

[49] B. Tian, K. Liu, Service-Oriented Approach to Facility Management Using Extended Building Information Modelling. Kunming, China, International Conference on Construction and Real Estate Management, 2014

[50] Z. Wang, T. Bulbul. J. Lucas, A case study of BIM-based model adaptation for healthcare facility management - information needs analysis, Computing in Civil Engineering (2015) 395-402

[51] F. Shalabi, Y. Turkan, IFC BIM-based facility management approach to optimize data collection for corrective maintenance. Journal of Performance of Constructed Facilities, 31(2017).

[52] P. Pishdad-Bozorgi, X. Gao, C, Eastman, A. P. Self, Planning and developing facility management-enabled building information model (FMenabled BIM). Automation in Construction, Volume 87 (2018) 22-38.

[53] S. Lee, Ö. Akin, Augmented reality-based computational fieldwork support for equipment operations and maintenance. Automation in Construction, Volume 20 (2011) 338-352

[54] Y.-C. Lin, Y.-C. Su, Y.-P. Chen, Developing Mobile BIM/2D Barcode-Based Automated Facility Management System. The Scientific World Journal, 2014.

[55] J. Irizarry, M. Gheisari, G. WilliamsK. , Roper, Ambient intelligence environments for accessing building information. Facilities, Volume 32, (2014) 120-138.

[56] G. Williams, M. Gheisari, P. Chen, J. Irizarry, BIM2MAR: an efficient BIM translation to mobile augmented reality applications. Journal of Management in Engineering , 31(Special Issue), 2015, pp. 1-8.

[57] W.L. Lee, et al., 2016. V3DM+: BIM interactive collaboration system for facility management. Visualization in Engineering.

[58] A. Borhani, H. W. Lee, C. S. Dossick, L. Osburn, BIM to Facilities Management: Presenting a Proven Workflow for Information Exchange. Seattle, Washington, International Workshop on Computing in Civil Engineering, 2017. 